\title{
Synthesis, Characterization and Antimicrobial Activity of Garcinol Capped Silver Nanoparticles ${ }^{\text {s }}$
}

\author{
H. N. Fernando ${ }^{1}$, K. G. U. R. Kumarasinghe ${ }^{1}$, T. D. C. P. Gunasekara ${ }^{2,3}$, H. P. S. K. Wijekoon ${ }^{2}$, E. M. A. K. \\ Ekanayaka $^{2}$, S. P. Rajapaksha ${ }^{1 *}$, S. S. N. Fernando ${ }^{2}$, and P. M. Jayaweera ${ }^{1}$ \\ ${ }^{1}$ Department of Chemistry, Faculty of Applied Sciences, University of Sri Jayewardenepura 10250, Sri Lanka \\ ${ }^{2}$ Department of Microbiology, Faculty of Medical Sciences, University of Sri Jayewardenepura 10250, Sri Lanka \\ ${ }^{3}$ Center for Plant Materials and Herbal Products Research, University of Sri Jayewardenepura 10250, Sri Lanka
}

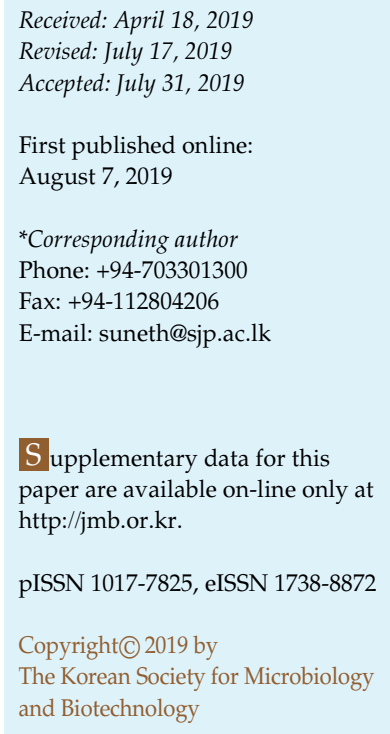

S upplementary data for this paper are available on-line only at http://jmb.or.kr.

pISSN 1017-7825, eISSN 1738-8872

Copyright(C) 2019 by

The Korean Society for Microbiology and Biotechnology

Garcinol, a well-known medicinal phytochemical, was extracted and isolated from the dried fruit rinds of Garcinia quaesita Pierre. In this study, garcinol has successfully used to reduce silver ions to silver in order to synthesize garcinol-capped silver nanoparticles (G-AgNPs). The formation and the structure of G-AgNPs were confirmed by UV-visible spectroscopy, transmission electron microscopy and Fourier transform infrared spectroscopy. The antimicrobial activity of garcinol and G-AgNPs were investigated by well diffusion assays, broth micro-dilution assays and time-kill kinetics studies against five microbial species, including Staphylococcus aureus (ATCC 25923), Pseudomonas aeruginosa (ATCC 27853), Escherichia coli (ATCC 25922), Candida albicans (ATCC 10231) and clinically isolated methicillin-resistant Staphylococcus aureus (MRSA). The formation of G-AgNPs is a promising novel approach to enhancing the biological activeness of silver nanoparticles, and to increase the water solubility of garcinol which creates a broad range of therapeutic applications.

Keywords: Garcinol, silver nanoparticles, garcinol-capped silver nanoparticles, antimicrobial activity, time-kill kinetics studies

\section{Introduction}

The antimicrobial effects of silver compounds have long been known and have been well-documented in literature [1-3]. They have been used to treat burns, wounds and bacterial infections for centuries [4-6]. On the other hand, antibiotics are at the forefront of the treatment of bacterial infections and inhibit bacterial metabolic pathways, leading to bactericidal activity $[7,8]$. However, the emergence of multidrug-resistant (MDR) bacterial strains has posed a major challenge in the treatment of infections by conventional antibiotics. MDR strains have evolved to overcome the antimicrobial activity of antibiotics by synthesizing novel proteins and developing new pathways that enable the bacteria to survive in the presence of the antibiotics [9-12]. Multidrug resistance has been reported in various regions in the world, indicating an emerging global threat. World Health Organization (WHO) reports have highlighted the need for urgent action from the pharmaceutical sector to develop novel and innovative approaches to controlling MDR bacterial strains [13-15].

Nanoparticle-based antimicrobial drugs have recently come into focus as a potential candidate to control bacterial infections. Nanoparticles have unique chemical, physical and biological properties [16]. The exceptionally high antimicrobial reactivity of metal nanoparticles is associated with both identified and unidentified toxic effects [17]. Among many types of metal nanoparticles, silver nanoparticles (AgNPs) are gaining significant attention due to their high antimicrobial properties. AgNPs bind and anchor to the surface of the cells [3,18,19], and intervene in many cellular activities, leading to cell apoptosis. AgNPs also act as growth inhibitors for yeast and exhibit antifungal action in various Candida species [20, 21]. Different modes of AgNPs' actions increase their potency for use in various medical applications, such as silver-based dressings, coatings, 
nano-gels, etc. [22-24].

The action of AgNPs on microorganisms is multifaceted. Many studies have provided evidence for multiple pathways leading to antimicrobial activity. The adhesion of positivelycharged AgNPs to the cellular surface was found to result in an altered membrane structure, leading to the leakage of cellular contents and impaired transportation of molecules [25]. Raffi et al. demonstrated by transmission electron microscopy (TEM) imaging that after a few minutes of contact, AgNPs caused the complete disruption of the cell membrane in E. coli [26]. Their study also revealed the formation of pits and morphological alterations in E. coli cells after treatment with AgNPs. Furthermore, they also reported ATP depletion due to leakage, disruption of membrane transport mechanisms and DNA condensation [26]. AgNPs may penetrate bacterial cells through porin channels present in gram-negative bacteria. Once inside the cell, the AgNPs may interact with various cellular structures, including ribosomes and cellular proteins, lipids and DNA, leading to the inhibition of protein synthesis and various vital cellular functions [27, 28]. The generation of reactive oxygen species (ROS) by AgNPs can increase the oxidative stress in cells, leading to various effects, including mitochondrial damage and the hyper-oxidation of lipids, proteins, and DNA. Increasing ROS levels consequently promotes cytotoxicity [29]. Many studies have described the antimicrobial activity of AgNPs against a wide range of microbial species [30]. The susceptibility of bacteria to functionalized metal nanoparticles has been reported, and this enhanced bioactivity is considered to be caused by the synergism between the nanoparticle and the functionalizing agent. Studies have reported the efficient antimicrobial activity of surface-modified nanoparticles with antibiotics, proteins, enzymes and phytochemicals [24, 31-37].

Garcinol, a phytochemical within the group of polyisoprenylated benzophenones, is isolated from fruit rinds of Garcinia quaesita Pierre, commonly known as brindle berry and Malabar tamarind. It is also termed Garcinia cambogia, G. gummi-gutta (L.), Cambogia gummi-gutta L. and G. gutta L., and has been frequently used in traditional medicine [38,39]. Garcinol is an established antioxidant and a potential anticancer agent, the efficacy of which could originate from the phenolic hydroxyl groups as well as the $\beta$-diketone moiety [40-43]. The antimicrobial activity of garcinol has been reported against Helicobacter pylori, MRSA species, etc. $[38,44,45]$. However, the low water solubility of garcinol has limited its clinical applications [47].

In this article, we report the synthesis and characterization of garcinol-capped AgNPs (G-AgNPs) and the determination of the antimicrobial activity against Staphylococcus aureus (ATCC 25923), Pseudomonas aeruginosa (ATCC 27853), Escherichia coli (ATCC 25922), Candida albicans (ATCC 10231) and clinically isolated MRSA species. To the best of our knowledge, the antimicrobial potential of G-AgNPs has not yet been reported.

\section{Materials and Methods}

\section{Materials}

Methanol, hexane, ethyl acetate, dichloromethane, silver nitrate, potassium hydroxide, trisodium citrate, sulphuric acid and (3(4,5-Dimethylthiazol-2-yl)- 2,5-diphenyltetrazolium bromide (MTT) were purchased from Sigma Aldrich (USA). Silica gel 60-120 mesh was purchased by Sisco Research Laboratories (Pvt) Ltd, India. Silica gel 100-200 mesh was obtained by Merck Specialities (Pvt) Ltd, India. Aluminum-backed standard thin-layer chromatography (TLC) plates (Merck, Germany) were used for the primary identification of garcinol. The Nuclear Magnetic Resonance (NMR) spectrum of garcinol was recorded on a $400 \mathrm{MHz}$ Bruker Ascend 400 Spectrometer (Bruker, USA). A freeze dryer (FreeZone Freeze Dry System, LABCONCO, USA) was used to dry the GAgNPs solutions. FTIR and UV-visible absorption spectra were recorded on a Thermo Scientific Nicolet iS10 FTIR spectrometer (USA) and a PerkinElmer Lambda 35 (USA), respectively. Transmission electron microscopy (TEM) images were recorded with JEOL-JEM-2100 High-Resolution Transmission Electron Microscope, USA.

Staphylococcus aureus (ATCC 25923), Pseudomonas aeruginosa (ATCC 27853), Escherichia coli (ATCC 25922), Candida albicans (ATCC 10231) and clinically isolated MRSA were obtained from the Department of Microbiology at the University of Sri Jayewardenepura. Mueller-Hinton agar (MHA) (Himedia, India) was used for the well diffusion assays. Mueller-Hinton Broth (MHB) (Himedia) was used to broth micro dilution assay. Nutrient agar (NA) (Himedia) was used in all bacteria-related tests while Sabouraud dextrose agar (SDA) (Himedia) was used in the analysis of Candida yeast species.

\section{Methods \\ Extraction and Isolation of Garcinol}

Fruits of Garcinia quaesita Pierre were collected from Kandy District, Central Province, Sri Lanka. The plant was authenticated by the National Herbarium, Department of National Botanical Gardens, Peradeniya, Sri Lanka. Garcinol was isolated according to the modified procedure reported by Kaur et al. [46]. Air-dried fruit rinds of G. quaesita were suspended in water overnight, cut into small pieces and oven-dried at $50^{\circ} \mathrm{C}$ for $48 \mathrm{~h}$. The dried rinds were ground with a mechanical grinder to obtain the powder form. Powered rinds of G. quaesita (500 g) were extracted to 
methanol by Soxhlet extraction, and then the methanol extract was concentrated under reduced pressure. The concentrated sticky, black-colored extract ( $35 \mathrm{~g}$ ) was further purified by solidmatrix adsorption followed by sequential partitioning into hexane, ethyl acetate and dichloromethane (DCM), respectively. The extracts were further purified in a 60-120 mesh silica gel chromatographic column (silica gel, hexane to ethyl acetate [6:4]). After drying the collected eluent fractions, the final product was purified garcinol, a yellow-colored powder $(0.85 \mathrm{~g})$ with a melting point in the range of $123-124^{\circ} \mathrm{C}[38,45,47]$.

\section{UV-Visible Spectroscopic and $\mathrm{pH}$ Studies}

A volume of $10 \mathrm{ml}$ of $1 \%$ garcinol in $0.1 \mathrm{M} \mathrm{KOH}$ stock solution was prepared $(\mathrm{pH}=11.6)$. UV-visible spectra were recorded for different $\mathrm{pH}$ values, decreasing the $\mathrm{pH}$ by adding known aliquots of $0.01 \mathrm{M} \mathrm{H}_{2} \mathrm{SO}_{4}$ at $25^{\circ} \mathrm{C}$. The spectra were recorded at 16 different $\mathrm{pH}$ values between $\mathrm{pH} 11.6$ and 2.1 [48].

\section{Synthesis and Characterization of Silver Nanoparticles (AgNPs)}

Silver nanoparticles (AgNPs) were chemically synthesized by reducing silver nitrate with trisodium citrate. The trisodium citrate $(1 \%, 5 \mathrm{ml})$ solution was added dropwise to $50 \mathrm{ml}$ of $0.001 \mathrm{M}$ $\mathrm{AgNO}_{3}$ solution at $100^{\circ} \mathrm{C}$. The mixture was continuously stirred until the mixture reached to room temperature and turned into pale yellow color. UV-visible spectra and TEM imaging was used in characterization of AgNPs [52].

\section{Preparation of G-AgNPs}

Garcinol solution $(1 \% \mathrm{~m} / \mathrm{v})$ was prepared by dissolving $0.100 \mathrm{~g}$ of garcinol powder in $10 \mathrm{ml}$ of $0.1 \mathrm{M} \mathrm{KOH}$. A volume of $5 \mathrm{ml}$ of this solution was added dropwise to $95 \mathrm{ml}$ of $0.003 \mathrm{M} \mathrm{AgNO}_{3}$ solution at $100^{\circ} \mathrm{C}$ and stirred until the temperature reached the room temperature $[49,50]$.

\section{Characterization of G-AgNPs}

The solution containing G-AgNPs was diluted to a 1:10 ratio in distilled water and UV-visible spectra were recorded at the spectral range of 200-600 nm. TEM imaging was performed using a drop-casting method on a holey carbon-coated $\mathrm{Cu}$ grid (accelerating voltage $=200 \mathrm{kV}$ ). The Fourier-transformed infrared (FTIR) spectrum of the freeze-dried sample was recorded with an FTIR spectrophotometer in a spectral range from 4,000 to $450 \mathrm{~cm}^{-1}$ at a resolution of $4 \mathrm{~cm}^{-1}$.

\section{Stability of G-AgNPs}

The synthesized solutions of G-AgNPs were stored at room temperature under normal room light conditions to test the photostability of the nanoparticles. The stability of AgNPs under electrolytic conditions was studied by adding aliquots of $5 \mathrm{M}$ $\mathrm{NaCl}$ into $2 \mathrm{ml}$ of G-AgNP solution. UV-visible spectra were obtained in the range of $350-800 \mathrm{~nm}$. The variability of the UVvisible absorbance with different $\mathrm{NaCl}$ concentrations was determined [51, 52].

\section{Determination of Antimicrobial Activity}

I. Agar diffusion assay. The antimicrobial activity of garcinol and G-AgNPs against Staphylococcus aureus (ATCC 25923), Pseudomonas aeruginosa (ATCC 27853), Escherichia coli (ATCC 25922), Candida albicans (ATCC 10231) and clinically isolated MRSA was determined using well diffusion assays. Organisms were cultured overnight at $37^{\circ} \mathrm{C}$ and the suspension of test organisms was prepared in sterilized saline. The standard inoculum of each organism was prepared by adjusting the suspension of 0.5 McFarland standard. Standard inoculum $(100 \mu \mathrm{l})$ was spread on MHA plates for bacteria or SDA plates for Candida. Wells were cut into the agar medium using a sterile $9 \mathrm{~mm}$ cork borer. The bottom of each well was sealed by adding molten agar. The wells were loaded with $150 \mu \mathrm{l}$ of $1.0 \mathrm{mg} / \mathrm{ml}$ of garcinol in $1 \%$ DMSO solution (A), $0.8 \mathrm{mg} / \mathrm{ml}$ of G-AgNPs solution (B), $0.4 \mathrm{mg} / \mathrm{ml} \mathrm{AgNP}$ solution (C), $10 \mathrm{mg} / \mathrm{ml}$ of Vancomycin/ Gentamycin antibiotic solution as the positive control (E) and sterile distilled water as negative control $(\mathrm{N})$. The culture plates were then incubated at $37^{\circ} \mathrm{C}$ for $24 \mathrm{~h}$. All experiments were triplicated. Diameters of zones of inhibition (ZOI) were measured and the average diameter was calculated [53].

II. Broth micro-dilution assay. Visual identification of minimum inhibitory concentration was done by broth micro-dilution assay. The assay was performed against five selected microbial species: Staphylococcus aureus (ATCC 25923), Pseudomonas aeruginosa (ATCC 27853), Escherichia coli (ATCC 25922), Candida albicans (ATCC 10231) and a clinical isolate of MRSA. Each organisms were cultured overnight at $37^{\circ} \mathrm{C}$ to prepare the suspensions of 0.5 McFarland $\left(1.5 \times 10^{8} \mathrm{CFU} / \mathrm{ml}\right)$ standards. The suspension was diluted 1000 times with sterilized saline to obtain final inoculums of $1.5 \times 10^{5} \mathrm{CFU} / \mathrm{ml}$. The stock solution of garcinol $(1,000 \mu \mathrm{g} / \mathrm{ml})$ was prepared in $1 \%$ DMSO. G-AgNPs $(800 \mu \mathrm{g} / \mathrm{ml})$ and AgNPs $(400 \mu \mathrm{g} / \mathrm{ml})$ solutions were prepared in distilled water. Doubledilution series of garcinol, G-AgNPs and AgNPs were prepared in sterilized MHB. A volume of $100 \mu \mathrm{l}$ from each dilution of garcinol, G-AgNPs and AgNPs were added to a 96 well plate. The plate was then incubated at $37^{\circ} \mathrm{C}$ for $24 \mathrm{~h}$ after inoculation $100 \mu \mathrm{l}$ of microbial suspension to each well. Finally, $50 \mu \mathrm{l}$ of $1 \%$ MTT was added to each well and incubated for $2-3 \mathrm{~h}$ before reading the plate [53].

III. Time-kill assay by plate-coating method. The plate-coating method was conducted using five microbial strains: Staphylococcus aureus (ATCC 25923), Pseudomonas aeruginosa (ATCC 27853), Escherichia coli (ATCC 25922), Candida albicans (ATCC 10231) and a clinical isolate of MRSA. Sterile Petri dishes with a diameter of $6 \mathrm{~cm}$ were coated with $800 \mu \mathrm{g} / \mathrm{ml}$ of garcinol and G-AgNPs by adding $2 \mathrm{ml}$ of each solution. A negative control plate was prepared by adding sterile distilled water. They were allowed to dry for $24 \mathrm{~h}$ inside a class II biological safety cabinet. Afterward, $2 \mathrm{ml}$ of standard bacterial suspension adjusted to $0.5 \mathrm{McF}$ arland standard was added to each coated Petri dish and incubated at room temperature. Aliquots of $100 \mu \mathrm{l}$ of the bacterial suspension were collected at different time intervals and spread on sterile 
NA/SDA plates. These plates were incubated at $37^{\circ} \mathrm{C}$ for $24 \mathrm{~h}$ for the bacterial species and $48 \mathrm{~h}$ for the $\mathrm{C}$. albicans before taking a viable cell count. Experiments were triplicated for each microbial species [51].

The average reduction percentages of colony-forming units (CFUs) obtained at different time intervals were calculated with the following equation:

Average percentage reduction $(\%)=$
$\frac{C F U \text { in } m l \text { of control }-C F U \text { in } m l \text { of test sample }}{\text { CFU in ml of control }} \times 100 \%$

All the graphs were prepared with OriginPro 8.5 and Omnic software (Thermo Fisher Scientific).

\section{Results and Discussion}

\section{Isolation and Characterization of Garcinol}

Garcinol (Fig. 1A) was isolated from dried fruit rinds of G. quaesita and appeared as pale-yellow needle crystals. The garcinol was water-insoluble, and when dissolved in methanol, yielded a yellow-colored solution (see supplementary information, Fig. S1 $[A])$. Extracted garcinol had a melting point at $123-124^{\circ} \mathrm{C} .{ }^{1} \mathrm{H} \mathrm{NMR}\left(\mathrm{CDCl}_{3}, 400 \mathrm{MHz}\right)$ and ${ }^{13} \mathrm{C} \mathrm{NMR}\left(\mathrm{CDCl}_{3}, 100 \mathrm{MHz}\right)$ spectra of extracted garcinol are recorded and presented in the supplementary information in Fig. S2. The spectroscopic features of the garcinol were compared with the literature and the purity was confirmed $[44,45]$. Peak wavelengths $\left(\lambda_{\max }[\log \varepsilon]\right)$ of UV-visible spectra of garcinol in methanol were observed at 240 (1.6), 282 (1.5) and 351 (0.7) nm (Fig. 1B).

Various physico-chemical parameters influence the pharmacokinetic and metabolic actions of phytochemicals. The acid dissociation constant $\left(p K_{a}\right)$ of phytochemicals is one such parameter that determines the absorption and bioavailability of the respective molecule [54]. The $p K_{a}$ value can be measured by changing the $\mathrm{pH}$ of the environment of the molecules and monitoring a property that varies with the ionization state of the molecule [55]. The spectrophotometric calculation of $p K_{a}$ is a popular method when the protonated and deprotonated forms of the molecule exhibit different spectral properties. The recorded UV-visible spectra of garcinol over the $\mathrm{pH}$ range of 1.8 to 11.6 (Figs. 2A and 2B) indicated the presence of two isosbestic points at $437 \mathrm{~nm}$ and $462 \mathrm{~nm}$, suggesting the presence of two $p K_{a}$ values for garcinol. The spectroscopically-calculated $p K_{a}$ values were 3.3 and 8.3 (Figs. $2 \mathrm{C}$ and 2D). The hydroxyl functional groups of garcinol (the phenolic hydroxyl groups and the hydroxyl group attached to cyclohexene moiety; see Fig. 1A) can be deprotonated at two different $\mathrm{pH}$ values. G-AgNPs are synthesized around $\mathrm{pH}$, at which point all of the hydroxyl groups are deprotonated, suggesting that garcinol attachment to the silver nanoparticle can occur by any of the three hydroxyl groups present in the garcinol molecule. The most favorable attachment would be bidentate with two phenolic hydroxyl groups, as shown in the supplementary information in Fig. S3. The structure of garcinol (Fig. 1A) includes two phenolic hydroxyl groups at the ortho position to each other and a $\beta$-diketone moiety [56]. As reported in the literature, compounds with at least two hydroxyl groups at the ortho or para position to each other have the potential to reduce $\mathrm{Ag}^{+}$and $\mathrm{Au}^{3+}$ to their respective metallic forms $[57,58]$. The reduced forms of ions lead to the formation of nano-sized metal clusters. Some polyphenols, such as tannic acid, have been used to reduce $\mathrm{Ag}^{+}$to $\mathrm{Ag}^{0}$ and form AgNPs. During the formation of AgNPs, the interaction of oxidized polyphenols with AgNPs through hydroxyl and/or quinone carbonyl groups contributes to their stabilization. Sivakumaran et al. reported that the free hydroxyl groups of gallic acid were oxidized
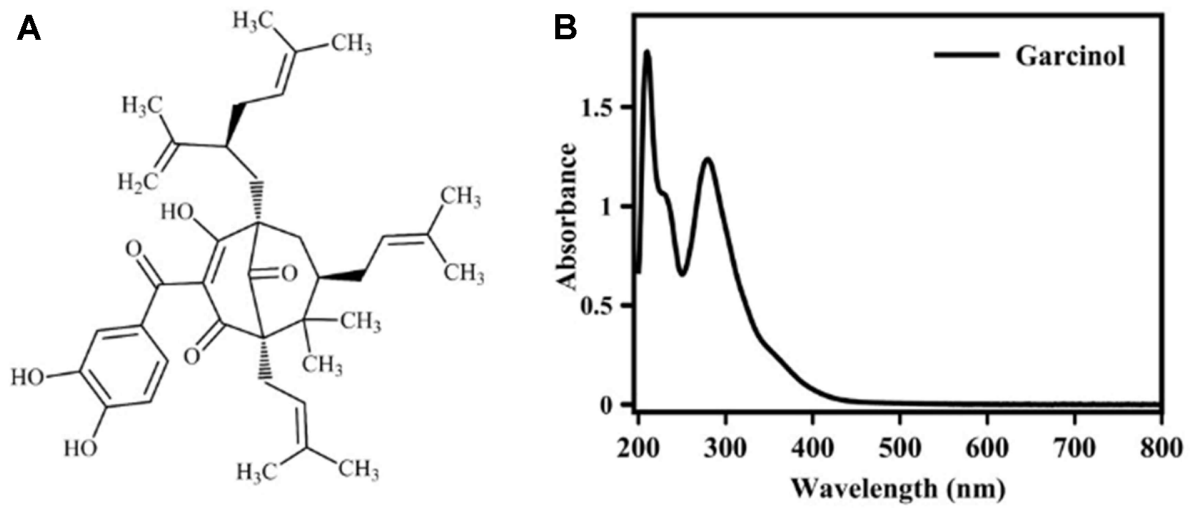

Fig. 1. (A) Chemical structure of garcinol. (B) UV-visible spectrum of garcinol in methanol. 

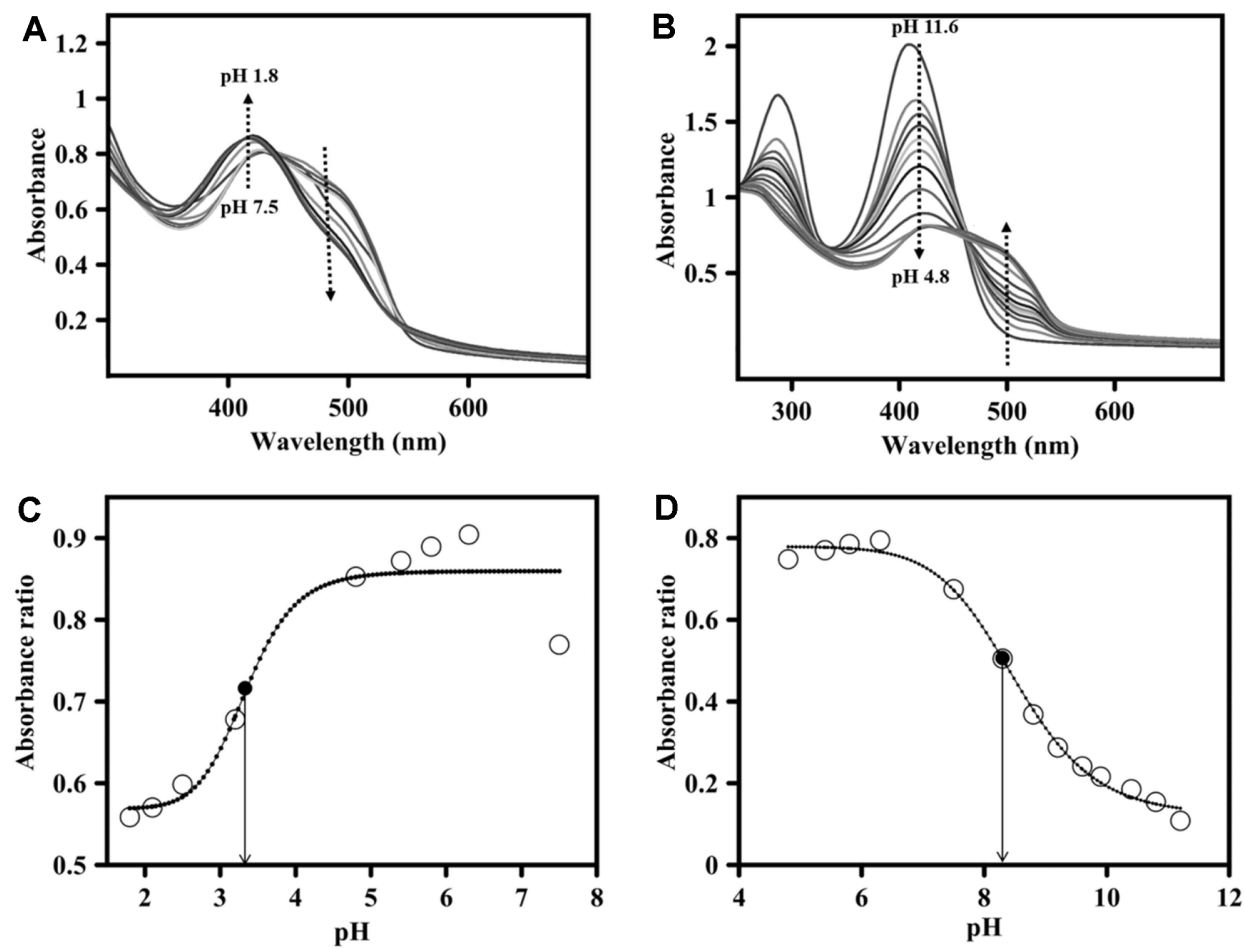

Fig. 2. (A) UV-visible spectra for the isosbestic point of garcinol in $\mathrm{pH} 7.5-1.8$ ( $\mathrm{pH} 7.5,6.3,5.8,5.4,4.8,3.2,2.5,2.1$, and 1.8 ). (B) UV-visible spectra for the isosbestic point of garcinol in $\mathrm{pH}$ 11.6-4.8 (pH 11.6, 11.2, 10.8, 10.4, 9.9, 9.6, 9.2, 8.8, 8.3, 7.5, 6.3, 5.8, 5.4, and 4.8). In $\mathrm{A}$ and $\mathrm{B}$, the direction of the arrows indicates the spectral change when the $\mathrm{pH}$ change from high to low. (C) Absorbance ratio vs. $\mathrm{pH}$ curve of garcinol in $\mathrm{pH}$ 1.8-7.5 (D) Absorbance ratio vs. $\mathrm{pH}$ curve of garcinol in $\mathrm{pH}$ 4.8-11.6.

to corresponding quinones, and $\mathrm{Au}^{3+}$ reduced to $\mathrm{Au}^{0}$ to form nanoparticles. The gold nanoparticles that formed were stabilized through the interaction of the carboxylic acid group of the gallic acid [57].

\section{Synthesis and Characterization of G-AgNPs and AgNPs}

G-AgNPs were obtained as a blackish-brown-colored,

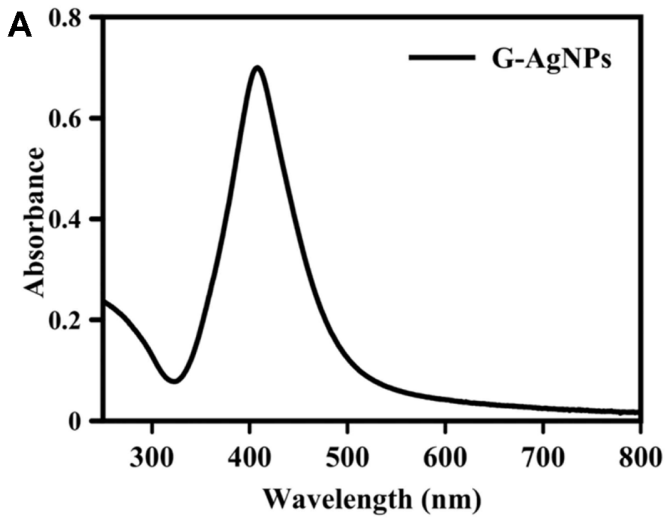

colloidal free, aqueous solution (see supplementary information, Fig. S1[B]). The concentration of G-AgNPs was $800 \mu \mathrm{g} / \mathrm{ml}$. UV-visible spectroscopic data revealed the formation of the surface plasmon resonance peak at $418 \mathrm{~nm}$, which confirmed the formation of silver nanoparticles (Fig. 3A). The G-AgNPs were stable for more than four months if kept under dark conditions. Furthermore, no

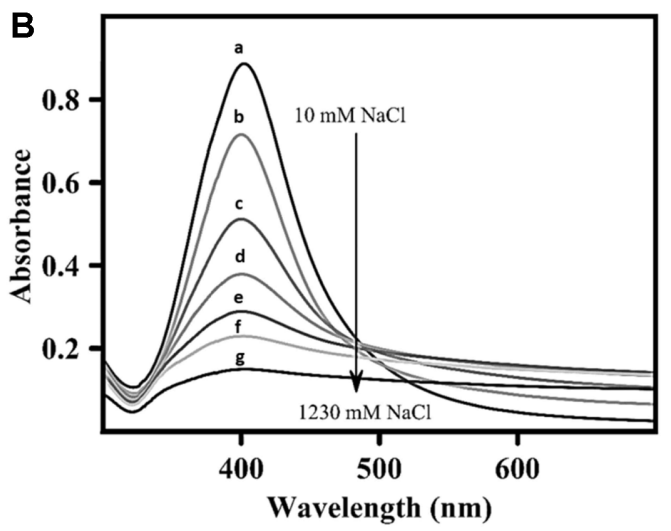

Fig. 3. (A) UV-visible spectrum of G-AgNPs. (B) Changes in UV-visible spectra of G-AgNPs with varying $\mathrm{NaCl}$ concentrations. The concentration of $\mathrm{NaCl}$ changes from $10 \mathrm{mM}$ to $1,230 \mathrm{mM}$ in the spectra $a$ to $g$. 
A

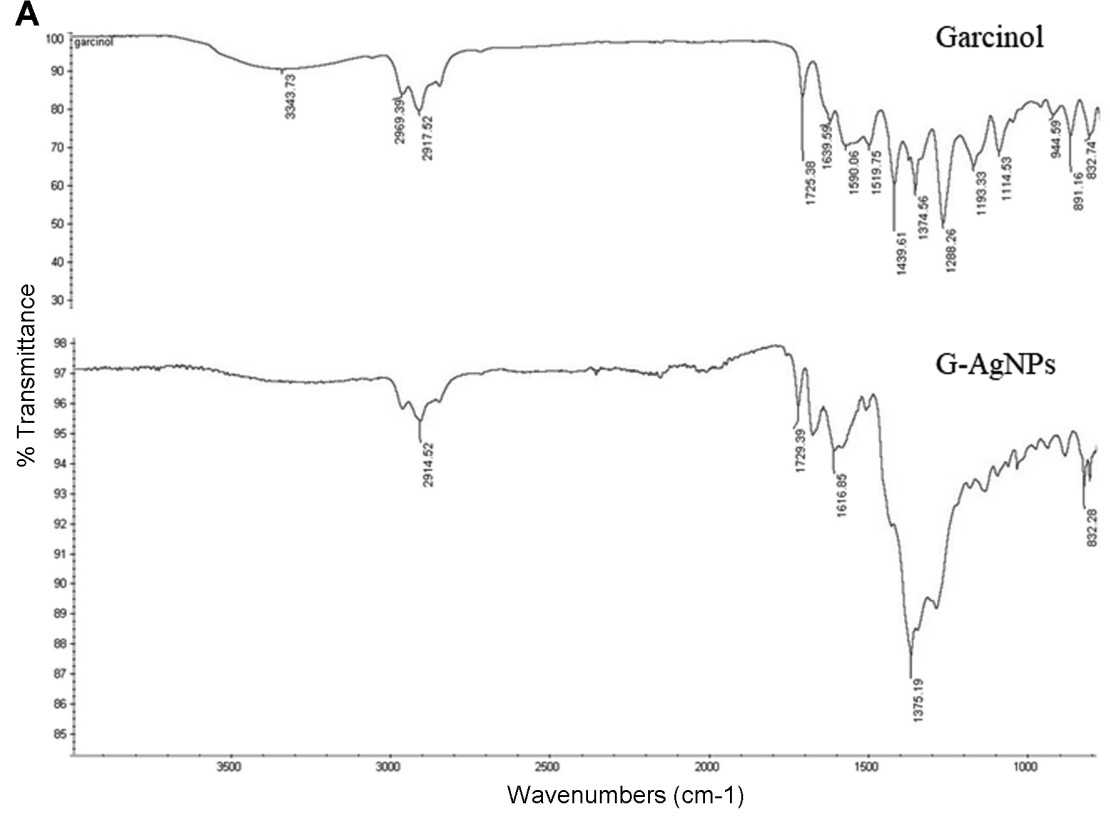

B

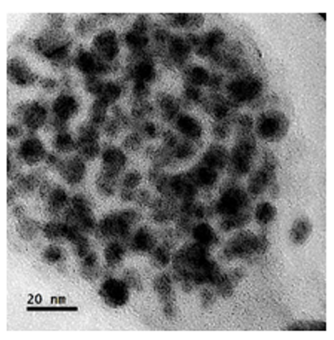

C

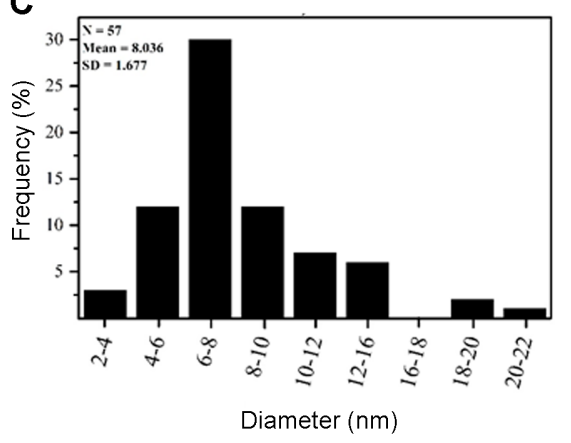

Fig. 4. (A). FTIR spectra of garcinol and G-AgNPs. (B) TEM image of G-AgNPs dispersed on a TEM copper gird with the scale of 20 nm. (C) Particle size distribution of G-AgNPs.

significant flocculation of the nanoparticles was observed with the increasing ionic strength of the solution $(10 \mathrm{mM}$ to $1,230 \mathrm{mM} \mathrm{NaCl}$ ), as shown in Fig. 3B. Chemically synthesized AgNPs were not stable at such a high ionic strength, leading to the immediate flocculation of nanoparticles even at lower concentrations of $\mathrm{NaCl}$. This indicated the stable formation of silver nanoparticles with garcinol, which prevented them from aggregating.

FTIR spectra of garcinol and G-AgNPs are shown in Fig. 4A. The G-AgNPs spectrum revealed distinct frequencies at $2,914,1,729,1,616,1,375 \mathrm{~cm}^{-1}$ (Fig. 4A), while the other specific features of FTIR spectrum of garcinol has faded into the spectrum of G-AgNPs. The TEM images revealed the spherical shape of G-AgNPs (Fig. 4B) and the size histogram confirmed the narrow distribution of the sizes of the nanoparticles (Fig. 4C). As shown in the histograms, the average diameter of the G-AgNPs was $8.0 \pm 0.17 \mathrm{~nm}$. The morphological characteristics and particle size of the nanoparticles vary according to many factors, especially with the chemical properties of the reducer and the stabilizer. Generally, smaller metal nanoparticles are reasoned to provide more potent biological activity [59]. Chemically synthesized AgNPs was obtained as a yellow colored, colloidal free, aqueous solution. UV-visible
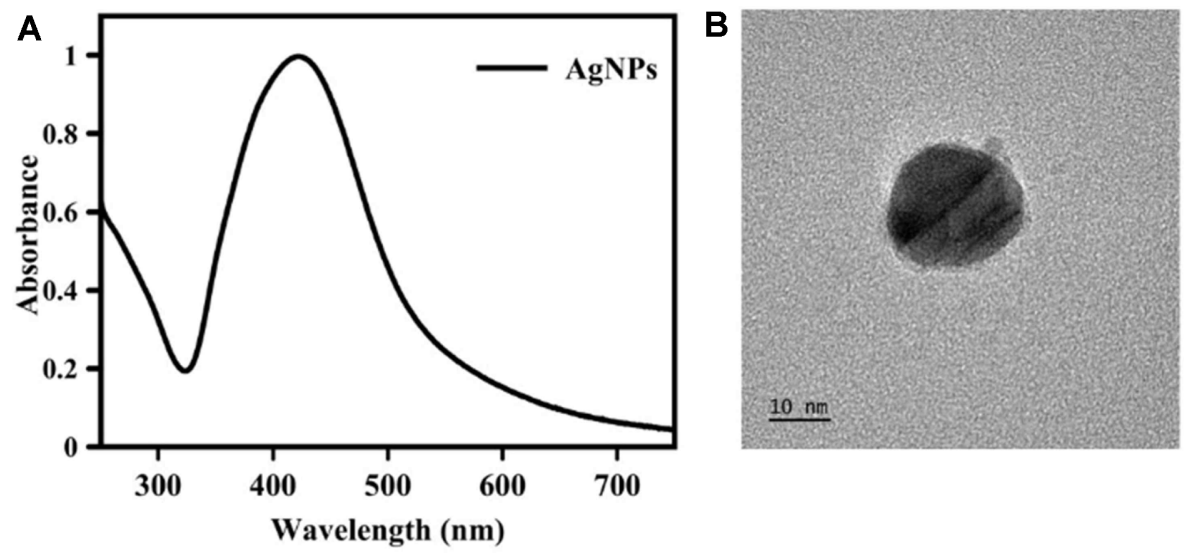

Fig. 5. (A) UV-visible spectrum of AgNPs. (B) TEM image of AgNPs dispersed on a TEM copper gird with the scale of $10 \mathrm{~nm}$. 
spectroscopic data revealed the formation of the surface plasmon resonance peak at $421 \mathrm{~nm}$ (Fig. 5A) which confirmed the formation of silver nanoparticles. The TEM images of the AgNPs revealed the diameter of the spherical shaped particles as 10-15 nm (Fig. 5B).

\section{Antimicrobial Activity}

Garcinol is commonly used as a flavoring agent and a food preservative, as well as a component of wound washes in traditional medicine $[41,43,44]$. The antimicrobial action of aqueous extracts of Garcinia zeylanica (G. zeylanica) fruit rinds has been demonstrated in previous studies. Senarathna et al. demonstrated that $\mathrm{TiO}_{2}$ surfaces modified with G. zeylanica aqueous extracts have considerable antimicrobial potential [60]. The garcinol is considered to have a strong MRSA inhibitory activity as suggested in the literature [45]. Evidences show that the minimum inhibitory concentration (MIC) of garcinol for MRSA is equivalent to one of the most prominent antibiotic vancomycin (MIC ranges of garcinol for MRSA $6.25-25 \mu \mathrm{g} / \mathrm{ml}$ ) [44]. The garcinol was shown to have antibacterial activity against Bascillus sp., S. aureus, and Listeria monocytogens. Furthermore, garcinol has a significant antimicrobial effect over Helicobacter pylori, a bacterium causing gastric ulcers in the stomach [44, 62-64].

The antimicrobial activity of G-AgNPs was determined through well diffusion assays, broth micro dilution assay, and time-kill kinetics studies. The results of the antimicrobial activity of the G-AgNPs studied by well diffusion assays showed different zones of inhibition (ZOIs) against the selected microbial species (Table 1). GAgNPs and AgNPs had shown a comparatively similar ZOI over selected gram-positive, gram-negative bacteria and Candida yeast species (see supplementary information, Fig. S4). The E. coli did not show any zone for garcinol in the well diffusion assays at the tested concentrations.
The garcinol has shown a significant ZOI over MRSA, $P$. aeruginosa and $S$. aureus. The strong antimicrobial activity of garcinol may be due to the presence of chelated hydroxyl groups in the first carbon because they can bind with the essential cations which are needed for the growth and survival of microorganisms [61]. The slight size reduction in the mean $\mathrm{ZOI}$ that was observed for the GAgNPs compared to garcinol may be due to the reduced diffusion of the nanoparticles with the increased particle size, which determines the diameter of the ZOI (see supplementary information, Fig. S4). Therefore, a direct contact method would be more suitable for determining the antimicrobial activity where G-AgNPs interact directly with the microbial surface. The absence of a ZOI of garcinol against E. coli was observed in the well diffusion assays suggests that a higher concentration may be necessary in order to effectively retard the growth of E. coli. Garcinol gave ZOIs for P. aeruginosa, S. aureus, MRSA and C. albicans.

The MIC of the garcinol, G-AgNPs and AgNPs were determined by broth micro-dilution assay against selected five microbial species (Table 2). The color change of MTT dye was used as the visual indication of MIC (see supplementary information, Fig. S5). $S$ aureus and MRSA showed the lowest MIC range $(1.95-3.91 \mu \mathrm{g} / \mathrm{ml})$ for garcinol but it was quiet higher $(62.5-125.0 \mu \mathrm{g} / \mathrm{ml})$ for the tested gram-negative microbial species.

The time-kill kinetics studies were performed to determine the direct contact time that resulted in 100\% inhibition of CFUs/ml for each microbial species. The time taken to reach the desired inhibition for various test organisms was found to vary (Fig. 6). G-AgNPs completely inhibited the growth of S. aureus in $90 \mathrm{~min}$ (Fig. 6A) while the $P$. aeruginosa and C. albicans yeast species were inhibited after $45 \mathrm{~min}$ of direct contact (Figs. 6B and 6C, respectively). MRSA took the longest time to achieve the complete inhibition (180 min; Fig. 6D) while E. coli was

Table 1. Antimicrobial activity of garcinol, G-AgNPs, and AgNPs.

\begin{tabular}{lccc}
\hline \multicolumn{1}{c}{ Name of Microbial Species } & \multicolumn{3}{c}{ Diameter of Mean Zone of Inhibitions (mm) } \\
\cline { 2 - 4 } & $\begin{array}{c}\text { Garcinol } \\
(1.0 \mathrm{mg} / \mathrm{ml})\end{array}$ & $\begin{array}{c}\text { G-AgNPs } \\
(0.8 \mathrm{mg} / \mathrm{ml})\end{array}$ & $\begin{array}{c}\text { AgNPs } \\
(0.4 \mathrm{mg} / \mathrm{ml})\end{array}$ \\
\hline Methicillin resistant Staphylococcus aureus & $24.7 \pm 0.5$ & $21.7 \pm 0.5$ & $22.0 \pm 0.8$ \\
Staphylococcus aureus (ATCC 25923) & $22.3 \pm 0.5$ & $15.7 \pm 0.5$ & $16.3 \pm 0.5$ \\
Pseudomonas aeruginosa (ATCC 27853) & $24.7 \pm 0.5$ & $18.0 \pm 0.8$ & $18.0 \pm 0.0$ \\
Candida albicans (ATCC 10231) & $17.7 \pm 0.5$ & $21.3 \pm 0.5$ & $21.7 \pm 0.5$ \\
Escherichia coli (ATCC 25922) & $9.0 \pm 0.0$ & $15.3 \pm 0.5$ & $40.3 \pm 0.5$ \\
\hline
\end{tabular}

All the data were triplicated.

*Vancomycin was used for gram positive bacteria, and gentamicin was used for gram negative bacteria and Candida species. 
Table 2. Minimum inhibitory concentrations of garcinol, G-AgNPs and AgNPs.

\begin{tabular}{lccc}
\hline \multirow{2}{*}{ Species } & \multicolumn{3}{c}{ Minimum inhibitory concentrations $(\mu \mathrm{g} / \mathrm{ml})$} \\
\cline { 2 - 4 } & Garcinol & G-AgNPs & AgNPs \\
\hline Methicillin resistant Staphylococcus aureus & $1.95-3.91$ & $12.5-25.0$ & $1.56-3.13$ \\
Staphylococcus aureus (ATCC 25923) & $1.95-3.91$ & $50.0-100.0$ & $12.5-25.0$ \\
Pseudomonas aeruginosa (ATCC 27853) & $62.5-125.0$ & $12.5-25.0$ & $1.56-3.13$ \\
Escherichia coli (ATCC 25922) & $62.5-125.0$ & $50.0-100.0$ & $12.5-25.0$ \\
Candida albicans (ATCC 10231) & $15.63-31.25$ & $25.0-50.0$ & $100.0-200.0$ \\
\hline
\end{tabular}
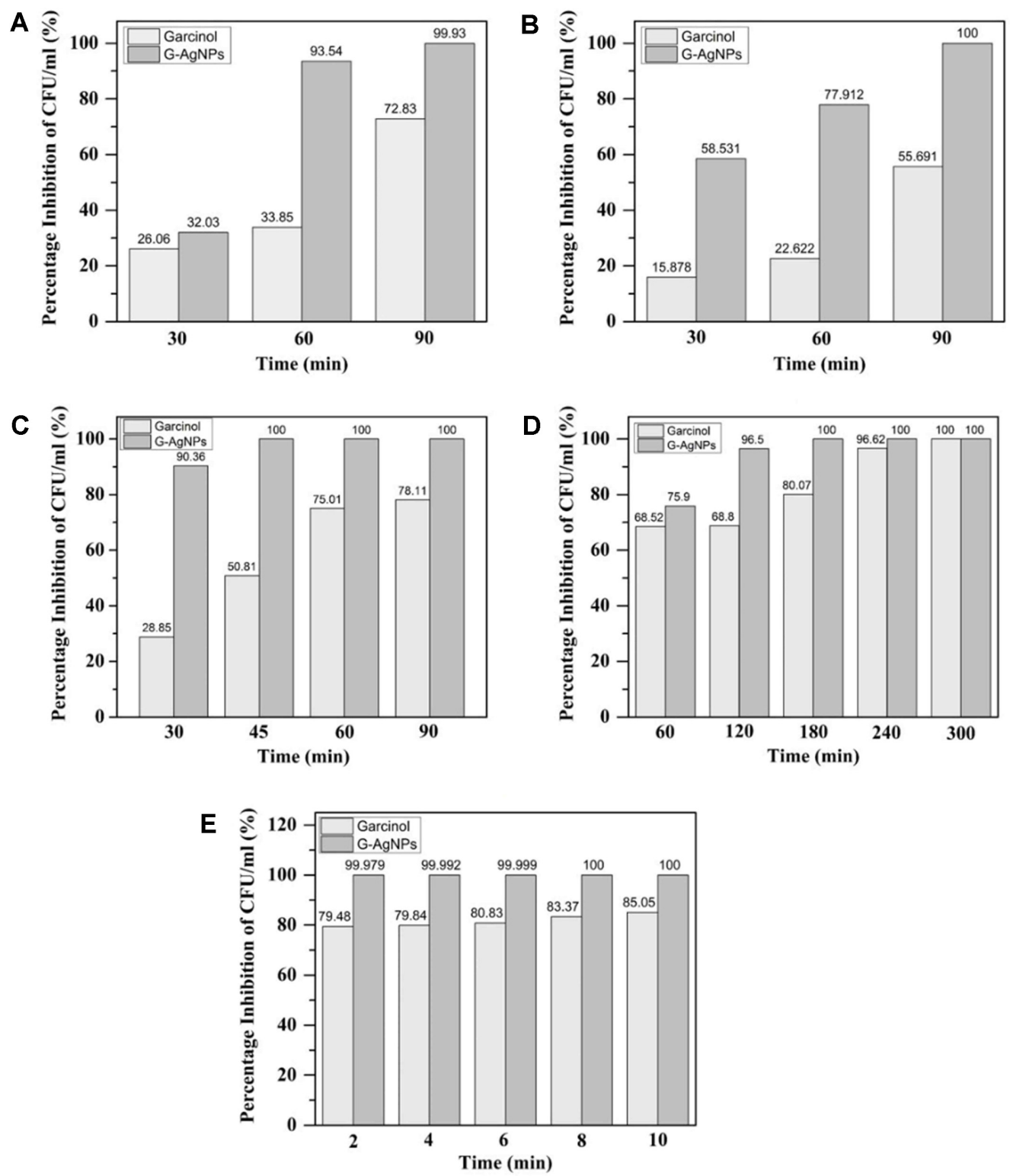

Fig. 6. Time-kill kinetics to determine the contact time occupied for the $100 \%$ inhibition of CFU $/ \mathrm{ml}$ in given microbial species. Given bar charts represent the percentage Inhibition of CFU/ml over contact time of (A) S. aureus, (B) P. aerugenosa, (C) C. albicans (D) MRSA and (E) E. coli microbial species. 
completely inhibited in 8 min (Fig. 6E).

The antimicrobial activity of synthesized G-AgNPs depends on several factors, such as the size and shape of nanoparticles and the different modes of action due to the presence of garcinol as well as the AgNPs. The nanoparticle size $(7-22 \mathrm{~nm})$ with a median size of $8 \mathrm{~nm}$ is favorable to enhance the stability and biocompatibility [65, 66]. Furthermore, due to their smaller size, these particles have a high surface-to-volume ratio, which facilitates more potent antimicrobial activity and interaction with the microorganisms. When the particle size decreases, it enables more effective penetration into the microbial cells, especially in gram-negative bacteria, due to their cell wall structure [17]. The comparatively short time required to achieve the inhibition of $E$. coli that was observed in this study suggests that E. coli is highly susceptible to G-AgNPs compared to $S$. aureus, thus supporting the findings of Kim et al. (2007), who reported that E. coli is inhibited at lower AgNPs concentrations in comparison to $S$. aureus [1]. This may be due to the interactions of the AgNPs with the cell membranes of gram-negative microorganisms, increasing membrane damages and leading to cell death. The nanoparticles in this study were found to be spherical. Evidence suggests that the antimicrobial properties against bacteria, viruses, and fungi are shape-dependent, with truncated triangular AgNPs having the most potent activity compared to spherical and rod-shaped nanoparticles [67]. The specific modes of action of garcinol on bacterial species are poorly understood. A significant synergistic effect was not observed in between garcinol and AgNPs. However, the clinical potency of garcinol is not completely characterized due to the low solubility in water. On the other hand, AgNPs are being tested heavily to identify their full clinical spectrum. Preparing G-AgNPs has increased the solubility of garcinol in water where garcinol can be tested with AgNPs to discover their mutual therapeutic efficacy.

\section{Acknowledgment}

This work was supported by University Grant ASP/01/ RE/SCI/2017/19 (University of Sri Jayewardenepura). Following organizations and people assisted to complete this work: Central Instrumentation Center (Faculty of Applied Sciences, University of Sri Jayewardenepura); Ms. Mudara Peiris, Ms. Ayomi Dilhari and Mr. Nuwan Dhanushka (University of Sri Jayewardenepura); Sri Lanka Institute of Nanotechnology (SLINTEC).

\section{Conflict of Interest}

The authors have no financial conflicts of interest to declare.

\section{References}

1. Kim JS, Kuk E, Yu KN, Kim JH, Park SJ, Lee HJ, et al. 2007. Antimicrobial effects of silver nanoparticles. Nanomedicine 3: 95-101.

2. Ruparelia JP, Chatterjee AK, Duttagupta SP, Mukherji S. 2008. Strain specificity in antimicrobial activity of silver and copper nanoparticles. Acta Biomater. 4: 707-716.

3. Sharma VK, Yngard RA, Lin Y. 2009. Silver nanoparticles: green synthesis and their antimicrobial activities. Adv. Colloid Interface Sci. 145: 83-96.

4. El Nour KMA, Eftaiha Aa, Al Warthan A, Ammar RA. 2010. Synthesis and applications of silver nanoparticles. Arabian J. Chem. 3: 135-140.

5. Dos Santos CA, Seckler MM, Ingle AP, Gupta I, Galdiero S, Galdiero, et al. 2014. Silver nanoparticles: therapeutical uses, toxicity, and safety issues. J. Pharm. Sci. 103: 1931-1944.

6. Ge L, Li Q, Wang M, Ouyang J, Li X, Xing MM. 2014. Nanosilver particles in medical applications: synthesis, performance, and toxicity. Int. J. Nanomedicine 9: 2399-2407.

7. Aminov RI. 2009. The role of antibiotics and antibiotic resistance in nature. Environ. Microbiol. 11: 2970-2988.

8. Martinez JL. 2009. The role of natural environments in the evolution of resistance traits in pathogenic bacteria. Proc. Biol. Sci. 276: 2521-2530.

9. Ahmad I, Beg AZ. 2001. Antimicrobial and phytochemical studies on 45 Indian medicinal plants against multi-drug resistant human pathogens. J. Ethnopharmacol. 74: 113-123.

10. Sambanthamoorthy K, Feng X, Patel R, Patel S, Paranavitana C. 2014. Antimicrobial and antibiofilm potential of biosurfactants isolated from lactobacilli against multi-drug-resistant pathogens. BMC Microbiol. 14: 197-205.

11. Hiramatsu K, Katayama Y, Matsuo M, Sasaki T, Morimoto Y, Sekiguchi A, et al. 2014. Multi-drug-resistant Staphylococcus aureus and future chemotherapy. J. Infect. Chemother. 20: 593601.

12. Karaiskos I, Giamarellou H. 2014. Multidrug-resistant and extensively drug-resistant Gram-negative pathogens: current and emerging therapeutic approaches. Expert Opin. Pharmacother. 15: $1351-1370$.

13. Powers JH. 2003. Development of drugs for antimicrobialresistant pathogens. Curr. Opin. Infect. Dis. 16: 547-551.

14. Burke JP. 2003. Infection control-a problem for patient safety. N. Engl. J. Med. 348: 651-656.

15. Angulo FJ, Collignon P, Powers JH, Chiller TM, AidaraKane A, Aarestrup FM. 2009. World Health Organization ranking of antimicrobials according to their importance in 
human medicine: a critical step for developing risk management strategies for the use of antimicrobials in food production animals. Clin. Infect. Dis. 49: 132-141.

16. Zhu X, Radovic-Moreno AF, Wu J, Langer R, Shi J. 2014. Nanomedicine in the management of microbial infectionoverview and perspectives. Nano Today 9: 478-498.

17. Wang L, Hu C, Shao L. 2017. The antimicrobial activity of nanoparticles: present situation and prospects for the future. Int. J. Nanomedicine 12: 1227-1249.

18. Yan X, He B, Liu L, Qu G, Shi J, Hu L, et al. 2018. Antibacterial mechanism of silver nanoparticles in Pseudomonas aeruginosa: proteomics approach. Metallomics 10: 557-564.

19. Khan SU, Saleh TA, Wahab A, Khan MHU, Khan D, Ullah Khan $W$, et al. 2018. Nanosilver: new ageless and versatile biomedical therapeutic scaffold. Int. J. Nanomedicine 13: 733762.

20. Panáček A, Kolář M, Večeřová R, Prucek R, Soukupova J, Krystof V, et al. 2009. Antifungal activity of silver nanoparticles against Candida spp. Biomaterials 30: 6333-6340.

21. Kim KJ, Sung WS, Suh BK, Moon SK, Choi JS, Kim JG, et al. 2009. Antifungal activity and mode of action of silver nanoparticles on Candida albicans. Biometals 22: 235-242.

22. Prabhu S, Poulose EK. 2012. Silver nanoparticles: mechanism of antimicrobial action, synthesis, medical applications, and toxicity effects. Int. Nano Lett. 2: 32-42.

23. Lara HH, Ayala-Núñez NV, Turrent LdCI, Padilla CR. 2010. Bactericidal effect of silver nanoparticles against multidrugresistant bacteria. World J. Microbiol. Biotechnol. 26: 615-621.

24. Fayaz AM, Balaji K, Girilal M, Yadav R, Kalaichelvan PT, Venketesan R. 2010. Biogenic synthesis of silver nanoparticles and their synergistic effect with antibiotics: a study against gram-positive and gram-negative bacteria. Nanomedicine 6: 103-109.

25. Durán $N$, Durán $M$, de Jesus $M B$, Seabra $A B$, Fávaro WJ, Nakazato G. 2016. Silver nanoparticles: A new view on mechanistic aspects on antimicrobial activity. Nanomedicine 12: 789-799.

26. Raffi M, Hussain F, Bhatti T, Akhter J, Hameed A, Hasan M. 2008. Antibacterial characterization of silver nanoparticles against E. coli ATCC-15224. J. Mater. Sci. Technol. 24: 192196.

27. Klueh U, Wagner V, Kelly S, Johnson A, Bryers J. 2000. Efficacy of silver-coated fabric to prevent bacterial colonization and subsequent device-based biofilm formation. J. Biomed. Mater. Res. 53: 621-631.

28. Rai M, Deshmukh S, Ingle A, Gade A. 2012. Silver nanoparticles: the powerful nanoweapon against multidrugresistant bacteria. J. Appl. Microbiol. 112: 841-852.

29. Rim K-T, Song S-W, Kim H-Y. 2013. Oxidative DNA damage from nanoparticle exposure and its application to workers' health: a literature review. Saf. Health Work 4: 177186.
30. Lara HH, Garza-Treviño EN, Ixtepan-Turrent L, Singh DK 2011. Silver nanoparticles are broad-spectrum bactericidal and virucidal compounds. J. Nanobiotechnology 9: 30-38.

31. Park Y, Hong Y, Weyers A, Kim Y, Linhardt R. 2011. Polysaccharides and phytochemicals: a natural reservoir for the green synthesis of gold and silver nanoparticles. IET Nanobiotechnol. 5: 69-78.

32. Lu R, Yang D, Cui D, Wang Z, Guo L. 2012. Egg whitemediated green synthesis of silver nanoparticles with excellent biocompatibility and enhanced radiation effects on cancer cells. Int. J. Nanomedicine 7: 2101-2107.

33. Amooaghaie R, Saeri MR, Azizi M. 2015. Synthesis, characterization and biocompatibility of silver nanoparticles synthesized from Nigella sativa leaf extract in comparison with chemical silver nanoparticles. Ecotoxicol. Environ. Saf. 120: $400-408$.

34. Sathishkumar G, Gobinath C, Karpagam K, Hemamalini V, Premkumar K, Sivaramakrishnan S. 2012. Phyto-synthesis of silver nanoscale particles using Morinda citrifolia L. and its inhibitory activity against human pathogens. Colloids Surf. B Biointerfaces 95: 235-240.

35. Blunk T, Hochstrasser DF, Sanchez JC, Müller BW, Müller RH. 1993. Colloidal carriers for intravenous drug targeting: plasma protein adsorption patterns on surface-modified latex particles evaluated by two-dimensional polyacrylamide gel electrophoresis. Electrophoresis 14: 1382-1387.

36. Gondikas AP, Morris A, Reinsch BC, Marinakos SM, Lowry GV, Hsu-Kim H. 2012. Cysteine-induced modifications of zero-valent silver nanomaterials: implications for particle surface chemistry, aggregation, dissolution, and silver speciation. Environ. Sci. Technol. 46: 7037-7045.

37. Alexander JW. 2009. History of the medical use of silver. Surg. Infect. (Larchmt) 10: 289-292.

38. Li F, Shanmugam MK, Chen L, Chatterjee S, Basha J, Kumar AP, et al. 2013. Garcinol, a polyisoprenylated benzophenone modulates multiple pro-inflammatory signaling cascades leading to suppression of growth and survival of head and neck carcinoma. Cancer Prev. Res. 6: 843-854.

39. Naldoni F, Claudino A, Cruz Jr J, Chavasco J, e Silva PF, Veloso MP, et al. 2009. Antimicrobial activity of benzophenones and extracts from the fruits of Garcinia brasiliensis. J. Med. Food 12: 403-407.

40. Liao C-H, Ho C-T, Lin J-K. 2005. Effects of garcinol on free radical generation and $\mathrm{NO}$ production in embryonic rat cortical neurons and astrocytes. Biochem. Biophys. Res. Commun. 329: 1306-1314.

41. Liu C, Ho PC-L, Wong FC, Sethi G, Wang LZ, Goh BC. 2015. Garcinol: Current status of its anti-oxidative, antiinflammatory and anti-cancer effects. Cancer Lett. 362:8-14.

42. Saadat N, Gupta SV. 2012. Potential role of garcinol as an anticancer agent. J. Oncol. 2012: 1-8.

43. Sang S, Liao C-H, Pan M-H, Rosen RT, Lin-Shiau S-Y, et al. 2002. Chemical studies on antioxidant mechanism of garcinol: 
analysis of radical reaction products of garcinol with peroxyl radicals and their antitumor activities. Tetrahedron 58: 10095-10102.

44. Tang W, Pan M-H, Sang S, Li S, Ho C-T. 2013. Garcinol from Garcinia indica: chemistry and health beneficial effects. In Tropical and Subtropical Fruits: Flavors, Color, and Health Benefits. pp. 133-145. 1129 $9^{\text {th }}$ Vol. ACS Publications American Chemical Society, Washington DC, USA.

45. Socolsky C, Plietker B. 2015. Total synthesis and absolute configuration assignment of MRSA active garcinol and isogarcinol. Chemistry 21: 3053-3061.

46. Kaur R, Chattopadhyay SK, Tandon S, Sharma S. 2012. Large scale extraction of the fruits of Garcinia indica for the isolation of new and known polyisoprenylated benzophenone derivatives. Ind. Crops Prod. 37: 420-426.

47. Gaonkar RH, Ganguly S, Dewanjee S, Sinha S, Gupta A, et al. 2017. Garcinol loaded vitamin E TPGS emulsified PLGA nanoparticles: preparation, physicochemical characterization, in vitro and in vivo studies. Sci. Rep. 7: 530-544.

48. Ossowski T, Goulart MO, Abreu FCd, Ana S, Euzébio A, Miranda P, et al. 2008. Determination of the pKa values of some biologically active and inactive hydroxyquinones. J. Braz. Chem. Soc. 19: 175-183.

49. Agnihotri S, Mukherji S, Mukherji S. 2014. Size-controlled silver nanoparticles synthesized over the range 5-100 nm using the same protocol and their antibacterial efficacy. RSC Adv. 4: 3974-3983.

50. Mulfinger L, Solomon SD, Bahadory M, Jeyarajasingam AV, Rutkowsky SA, Boritz C. 2007. Synthesis and study of silver nanoparticles. J. Chem. Educ. 84: 322-325.

51. Peiris M, Fernando S, Jayaweera P, Arachchi N, Guansekara T. 2018. Comparison of antimicrobial properties of silver nanoparticles synthesized from selected bacteria. Indian J. Microbiol. 58: 301-311.

52. Rashid MU, Bhuiyan MKH, Quayum ME. 2013. Synthesis of silver nano particles (Ag-NPs) and their uses for quantitative analysis of vitamin C tablets. Dhaka Univ. J. Pharm. Sci. 12: 29-33.

53. Balouiri M, Sadiki M, Ibnsouda SK. 2016. Methods for in vitro evaluating antimicrobial activity: A review. J. Pharm. Anal. 6: 71-79.

54. Tutone M, Lauria A, Almerico AM. 2016. Theoretical determination of the $\mathrm{pK}$ a values of betalamic acid related to the free radical scavenger capacity: comparison between empirical and quantum chemical methods. Interdiscip. Sci. 8: 177-185.
55. Babić S, Horvat AJ, Pavlović DM, Kaštelan-Macan M. 2007. Determination of $\mathrm{pKa}$ values of active pharmaceutical ingredients. Trends Analyt. Chem. 26: 1043-1061.

56. Kumar N, Singh AK. 2014. Plant profile, phytochemistry and pharmacology of Avartani (Helicteres isora Linn.): a review. Asian Pac. J. Trop. Biomed. 4: S22-S26.

57. Sivaraman SK, Elango I, Kumar S, Santhanam V. 2009. A green protocol for room temperature synthesis of silver nanoparticles in seconds. Curr. Sci. 97: 1055-1059.

58. Yoosaf K, Ipe BI, Suresh CH, Thomas KG. 2007. In situ synthesis of metal nanoparticles and selective naked-eye detection of lead ions from aqueous media. J. Phys. Chem. C 111: $12839-12847$.

59. Makarov V, Love A, Sinitsyna O, Makarova S, Yaminsky I, Taliansky ME, et al. 2014. "Green" nanotechnologies: synthesis of metal nanoparticles using plants. Acta Naturae 6: 35-44.

60. Senarathna U, Fernando S, Gunasekara T, Weerasekera M, Hewageegana $\mathrm{H}$, Arachchi NDH, et al. 2017. Enhanced antibacterial activity of $\mathrm{TiO}_{2}$ nanoparticle surface modified with Garcinia zeylanica extract. Chem. Cent. J. 11: 1-7.

61. Padhye S, Ahmad A, Oswal N, Sarkar FH. 2009. Emerging role of Garcinol, the antioxidant chalcone from Garcinia indica Choisy and its synthetic analogs. J. Hematol. Oncol. 2: 38-51.

62. Cuesta-Rubio O, Piccinelli AL, Rastrelli L. 2005. Chemistry and biological activity of polyisoprenylated benzophenone derivatives. In Studies in natural products chemistry. pp. 671720. $32^{\text {nd }}$ volume. Elsevier, Amsterdam, The Netherlands.

63. Tharachand C, Selvaraj CI, Abraham Z. 2015. Comparative evaluation of anthelmintic and antibacterial activities in leaves and fruits of Garcinia cambogia (Gaertn.) desr. and Garcinia indica (Dupetit-Thouars) choisy. Braz. Arch. Biol. Technol. 58: 379-386.

64. Varalakshmi K, Sangeetha C, Shabeena A, Sunitha S, Vapika J. 2010. Antimicrobial and cytotoxic effects of Garcinia indica fruit rind extract. Am. Eurasian J. Agric. Environ. Sci. 7: 652656.

65. Kim J-Y, Kim S-E, Kim J-E, Lee J-C, Yoon J-Y. 2005. The biocidal activity of nano-sized silver particles comparing with silver ion. J. Korean Soc. Environ. Eng. 27: 771-776.

66. Kim S-H, Lee H-S, Ryu D-S, Choi S-J, Lee D-S. 2011. Antibacterial activity of silver-nanoparticles against Staphylococcus aureus and Escherichia coli. Korean J. Microbiol. Biotechnol. 39: 77-85.

67. Chen S, Carroll DL. 2002. Synthesis and characterization of truncated triangular silver nanoplates. Nano Lett. 2: 10031007. 